\title{
ANALISIS PENGARUH VARIABEL ANTISEDAN DARI IMPULSE BUYING (STUDI EMPIRIS PADA GIANT EKSTRA JATIASIH)
}

\author{
Teofilus \\ Universitas Ciputra Surabaya \\ Steven $\mathrm{Ng}$ \\ Supply Chain and Sales Div, PT. Permata Dunia Sukses Utama
}

\begin{abstract}
ABSTRAK
Perkembangan dalam bisnis ritel di Indonesia terus mengalami pertumbuhan yang positif dalam 10 tahun terakhir. Untuk menghadapi persaingan yang semakin ketat, Setiap perusahaan ritel perlu memperhatikan perilaku konsumen di dalam toko seperti pembelian yang tidak direncanakan. Salah satu faktor yang mempengaruhi Impulse Buying adalah lingkungan toko dimana semua gerai ritel memiliki lingkungan tokonya sendiri. Tujuan penelitian ini tak lain untuk mengetahui sejauh mana peran lingkungan toko, Impulse Buying tendency, Shopping Enjoyment Tendency, Positive Affect, Negative Affect dan urge dalam mempengaruhi pembelian yang tidak direncanakan. Hasil menunjukkan bahwa terdapat faktor-faktor lingkungan toko seperti musik, Layout, dan karyawan dapat berpengaruh secara signifikan dalam menciptakan pengaruh positif didalam toko, Serta faktor Layout yang memberikan pengaruh secara signifikan dalam menciptakan dorongan untuk melakukan pembelian yang tidak direncanakan. Faktor kepribadian konsumen seperti Impulse Buying tendency pun diketahui memberikan pengaruh yang signifikan terhadap terjadinya dorongan untuk melakukan pembelian yang tidak direncanakan.
\end{abstract}

Kata Kunci : Lingkungan toko, musik, pencahayaan, Layout, Karyawan, Impulse Buying, Shopping Enjoyment Tendency, Impulse Buying tendency, Positive Affect, Negative Affect, Impulse Buying 


\section{Teofilus}

\section{Steven $\mathrm{Ng}$}

\section{PENDAHULUAN}

Hero Supermarket berada di bawah naungan jaringan ritel global besar yang bernama Hero Group yang di miliki oleh Dairy Farm Management Service Ltd. Pada tahun 2013, bisnis unit Giant menjalani perubahan identitas dari Giant Hypermarket dan Giant Supermarket menjadi Giant Ekstra dan Ekspres.

Menurut Mohan, Sivakuraman \& Sharma (2013) Store Environment meliputi kombinasi dari beberapa elemen di dalam toko yaitu musik, pencahayaan, Layout dan karyawan toko. Banyak peneliti-peneliti sebelumnya yang telah meneliti dampak dari Store Environment terhadap number of items purchased, Store liking, time dan money spent (Sherman, Marthur \& Smith 1997 dalam Mohan et al. 2013), perceived quality of merchandise and patronage (Baker, Parasuraman \& Grewal 1994 dalam Mohan et al. 2013), namun hanya sedikit yang memberikan perhatian lebih terhadap dampak dari Store Environment terhadap Impulse Buying (Hu and Jasper 2006 dalam Mohan et al. 2013).

Berdasarkan penjelasan diatas maka peneliti tertarik untuk meneliti apakah faktor-faktor yang ada didalam lingkungan toko dapat mempengaruhi seseorang untuk melakukan pembelian tanpa rencana karena seperti yang kita ketahui bahwa setiap toko memiliki lingkungan toko dan lingkungan toko merupakan faktor didalam bisnis ritel yang dapat di kendalikan oleh manajemen toko tersebut. Berdasarkan penjelasan diatas maka penulis memilih judul yaitu "ANALISIS PENGARUH VARIABEL ANTISEDAN DARI IMPULSE BUYING" (Studi Empiris pada Giant Ekstra Jatiasih)

\section{PEMBATASAN MASALAH}

Penelitian ini hanya berfokus kepada pengaruh musik, pencahayaan, Layout, karyawan, Shopping Enjoyment Tendency serta Impulse Buying Tendency dan Positive Affect, Negative Affect dan Urge to buy impulsively sebagai variabel intervening terhadap Impulse Buying pada gerai Giant Ekstra yang terletak di Jatiasih, Bekasi.

\section{RUMUSAN MASALAH}

Berdasarkan latar belakang dan pembatasan masalah, maka rumusan masalah dalam penelitian ini adalah :

1. Apakah variabel musik memiliki pengaruh terhadap variabel Positive Affect?

2. Apakah variabel pencahayaan memiliki pengaruh terhadap variabel Positive Affect?

3. Apakah variabel Layout memiliki pengaruh terhadap variabel Positive Affect?

4. Apakah variabel karyawan memiliki pengaruh terhadap variabel Positive Affect?

5. Apakah variabel musik memiliki pengaruh terhadap variabel Negative Affect?

6. Apakah variabel pencahayaan memiliki pengaruh terhadap variabel Negative Affect?

7. Apakah variabel Layout memiliki pengaruh terhadap variabel Negative Affect?

8. Apakah variabel karyawan memiliki pengaruh terhadap variabel Negative Affect?

9. Apakah variabel musik memiliki pengaruh terhadap variabel Urge to buy impulsively?

10. Apakah variabel pencahayaan memiliki pengaruh terhadap variabel Urge to buy impulsively?

11. Apakah variabel Layout memiliki pengaruh terhadap variabel Urge to buy impulsively?

12. Apakah variabel karyawan memiliki pengaruh terhadap variabel Urge to buy impulsively? 


\section{Jurnal Manajemen Teori dan Terapan \\ Tahun 10. No. 1, April 2017}

13. Apakah variabel Shopping Enjoyment Tendency memiliki pengaruh terhadap variabel Positive Affect?

14. Apakah variabel Impulse Buying tendency memiliki pengaruh terhadap variabel Urge to buy impulsively?

15. Apakah variabel Positive Affect memiliki pengaruh terhadap variabel Urge to buy impulsively?

16. Apakah variabel negative afffect memiliki pengaruh terhadap variabel Urge to buy impulsively?

17. Apakah variabel Urge to buy impulsively memiliki pengaruh terhadap variabel Impulse Buying?

\section{TUJUAN PENELITIAN}

Berdasarkan latar belakang dan pembatasan masalah, maka rumusan masalah dalam penelitian ini adalah :

1. Apakah variabel musik memiliki pengaruh terhadap variabel Positive Affect?

2. Apakah variabel pencahayaan memiliki pengaruh terhadap variabel Positive Affect?

3. Apakah variabel Layout memiliki pengaruh terhadap variabel Positive Affect?

4. Apakah variabel karyawan memiliki pengaruh terhadap variabel Positive Affect?

5. Apakah variabel musik memiliki pengaruh terhadap variabel Negative Affect?

6. Apakah variabel pencahayaan memiliki pengaruh terhadap variabel Negative Affect?

7. Apakah variabel Layout memiliki pengaruh terhadap variabel Negative Affect?

8. Apakah variabel karyawan memiliki pengaruh terhadap variabel Negative Affect?

9. Apakah variabel musik memiliki pengaruh terhadap variabel Urge to buy impulsively?

10. Apakah variabel pencahayaan memiliki pengaruh terhadap variabel Urge to buy impulsively?

11. Apakah variabel Layout memiliki pengaruh terhadap variabel Urge to buy impulsively?

12. Apakah variabel karyawan memiliki pengaruh terhadap variabel Urge to buy impulsively?

13. Apakah variabel Shopping Enjoyment Tendency memiliki pengaruh terhadap variabel Positive Affect?

14. Apakah variabel Impulse Buying tendency memiliki pengaruh terhadap variabel Urge to buy impulsively?

15. Apakah variabel Positive Affect memiliki pengaruh terhadap variabel Urge to buy impulsively?

16. Apakah variabel negative affect memiliki pengaruh terhadap variabel Urge to buy impulsively?

17. Apakah variabel Urge to buy impulsively memiliki pengaruh terhadap variabel Impulse Buying?

\section{TINJAUAN PUSTAKA}

\section{LINGKUNGAN TOKO}

Menurut Dunne \& Lusch (2005 dalam Rahmasari 2010) Lingkungan toko merupakan salah satu faktor dalam riteling yang penting mengingat bahwa $70 \%$ dari pembelian ternyata merupakan Impulse Buying atau pembelian yang tidak direncanakan. Melalui elemenelemen yang ada di Lingkungan toko yaitu Store planning (Layout dan design), visual merchandising dan visual communication, Riteler dapat menciptakan stimulti-stimulti yang 


\section{Teofilus}

\section{Steven $\mathrm{Ng}$}

akan memicu konsumen untuk berbelanja lebih banyak daripada yang sudah di rencanakan sebelumnya. Ditambahkan oleh Mohan et al., (2013) bahwa Lingkungan toko adalah persepsi kombinasi dari unsur-unsur musik, pencahayaan, Layout dan karyawan yang dimana dalam penelitian ini peneliti menjadikan unsur-unsur musik, pencahayaan, Layout dan karyawan sebagai variabel dan bukan sebagai dimensi.

\section{MUSIK}

Salah satu unsur dalam lingkungan toko adalah musik dimana menurut Jain \& Ranish (2011) telah diamati sebagai rangsangan yang kuat dalam membentuk ritel experience. Musik digunakan untuk membentuk perhatian, identifikasi, asosiasi dan pengingat di ritel. Sebagai kunci dari ambient factors di dalam lingkungan toko ritel, musik terlibat dalam menghibur, memberikan energi, menyegarkan, serta menciptakan pengalaman yang tak terlupakan bagi konsumen. Hal tersebut diperkuat Henrington \& Capella (1994 dalam Jain \& Rajnish 2011) latar belakang musik memiliki dampak langsung kepada pengalaman berbelanja dengan mempengaruhi keputusan pembelian, evaluasi secara keseluruhan dan evaluasi pelayanan. Musik juga di ketahui efektif dalam membangun mood (Sweeney \& Wiber 2002)

\section{PENCAHAYAAN}

Unsur lain selain musik adalah pencahayaan, dimana menurut Chan (1991 dalam Hsu 2010) pencahayaan dapat membuat konsumen mengidentifikasi produk dengan baik. Penerangan yang baik dapat memperkuat retina mata sehingga dapat mengidentifikasi benda-benda kecil dan mencegah mata konsumen agar tidak lelah.

\section{LAYOUT}

Unsur lainnya adalah Layout, dimana menurut Merrilees dan Miller (2001 dalam Vrechopoulos 2004) adalah salah satu aspek penting dalam menciptakan Store loyalty, dan Simonson (1999 dalam Vrechopoulos 2004) menyatakan bahwa Store Layout design dapat memainkan peran penting tidak hanya memuaskan keinginan konsumen namun juga mempengaruhi keinginan dan preferensi konsumen.

\section{EMPLOYEE}

Unsur yang terakhir adalah Employee, dimana menurut Eroglu \& Machleit (1990 dalam Baker et al. 2002) merupakan salah satu dari unsur sosial. Employee memainkan peranan yang penting dalam mempengaruhi mood dan kepuasan konsumen (Grewal \& Sharma 1991 dalam Baker et al. 2002).

\section{SHOPPING ENJOYMENT TENDENCY}

Shopping Enjoyment Tendency menurut Beatty \& Ferrell (1998) adalah sebagai perasaan senang seseorang yang di dapatkan dalam proses berbelanja. Konsumen juga mendapatkan kegembiraan dan kesenangan dari kegiatan berbelanja (Babin, Darden \& Griffin 1994 dalam Mohan et al. 2013).

Variabel ini juga merupakan konseptualiasasi dari variabel perbedaan individu (Beatty \& Ferrell 1998). Sebagi contoh, Lenger \& Korgaonkar (1980 dalam Beatty \& Ferrell 1998) menyebut individu yang menikmati proses belanja sebagai recreational shoppers. Mereka menemukan bahwa konsumen ini yang menggunakan lebih banyak waktu untuk belanja. 


\section{IMPULSE BUYING TENDENCY}

Impulse Buying tendency menurut Silvera, Lavack \& Kropp (2008) mengacu kepada banyak dimensi personalia: individu yang memiliki Impulse Buying tendency yang kuat kecenderungan rendah dalam membangun kesadaran, otonomi, dan kebutuhan pribadi yang terstruktur.

Kemudian Beatty \& Ferrell (1998 dalam Wells, Parboleah \& Valacich 2011) menambahkan bahwa Impulse Buying tendency didefinisikan sebagai dua kecenderungan, (1) mengalami keadaan spontan dan tiba-tiba terdorong untuk melakukan pembelian ditempat (2) bertindak berdasarkan dorongan yang dirasakan dengan sedikit pertimbangan dan evaluasi atas konsekuensi yang akan terjadi.

\section{POSITIVE AFFECT}

Menurut Beatty \& Ferrell (1998) Positive Affect adalah pengaruh positif yang mencerminkan sejauh mana seseorang merasa antusias, aktif dan waspada. Ini adalah keadaan dengan energi yang besar, penuh konsentrasi dan menyenangkan. Seseorang di pengaruhi oleh suasana hati mereka yang sudah ada, afektif disposisi, dan reaksi mereka terhadap lingkungan toko. Jadi variabel ini adalah penggabungan kompleks individu dan variabel situasional.

\section{NEGATIVE AFFECT}

Menurut Beatty \& Ferrell (1998), Negative Affect mencerminkan keterlibatan pengaruh negatif seperti perasaan tertekan, tidak senang, permusuhan, kemarahan, rasa bersalah, rasa takut, dan lain-lain.

Sedangkan menurut Clark \& Isen (1982 dalam Beatty \& Ferrell 1998) pengaruh dari Negative Affect terhadap perilaku masih belum jelas. Terkadang Negative Affect menghasilkan efek yang hampir sama dengan Positive Affect, namun di saat yang lain Negative Affect juga menghasilkan kebalikan dari Positive Affect.

\section{URGE TO BUY IMPULSIVELY}

Menurut Beatty \& Ferrell (1998) Urge to buy impulsively adalah perasaan kuat dimana ada dorongan untuk membeli sesuatu di saat menghadapi sebuah objek dalam lingkungan toko. Ini jelas adalah tindakan sebelum melakukan pembelian yang tidak direncanakan. Sesuai dengan literatur, kejadian itu adalah spontan dan tiba-tiba. Dan di perkuat oleh Piron (1991 dalam Wells at al. 2011) dimana Urge to buy impulsively di gambarkan sebagai suatu keadaan hedonically complex, tiba-tiba dan kadang-kadang tak tertahankan serta terjadi secara terus-menerus.

\section{IMPULSE BUYING}

Menurut Rook (1987 dalam Podoshen \& Andrzejewski 2012) sebagai perilaku pembelian berdasarkan stimulus yang diterima dan disertai perasaan kegembiraan, kesenangan dan dorongan yang kuat untuk membeli tanpa memikirkan konsekuesi dan impilkasi dari pembelian di masa yang akan datang. Di perkuat oleh pernyataan Piron (1991: 512 dalam Wells et al. 2011) Impulse Buying merupakan pembelian yang tidak terencana, sebagai hasil dari stimulus dan diputuskan di tempat saat itu juga. Impulse Buying juga merupakan fenomena yang penting dalam konteks bisnis ritel dan marketing (Verplanken dan Sato 2011 dalam Duarte, Raposo \& Ferraz 2013).

\section{PARADIGMA PENELITIAN}




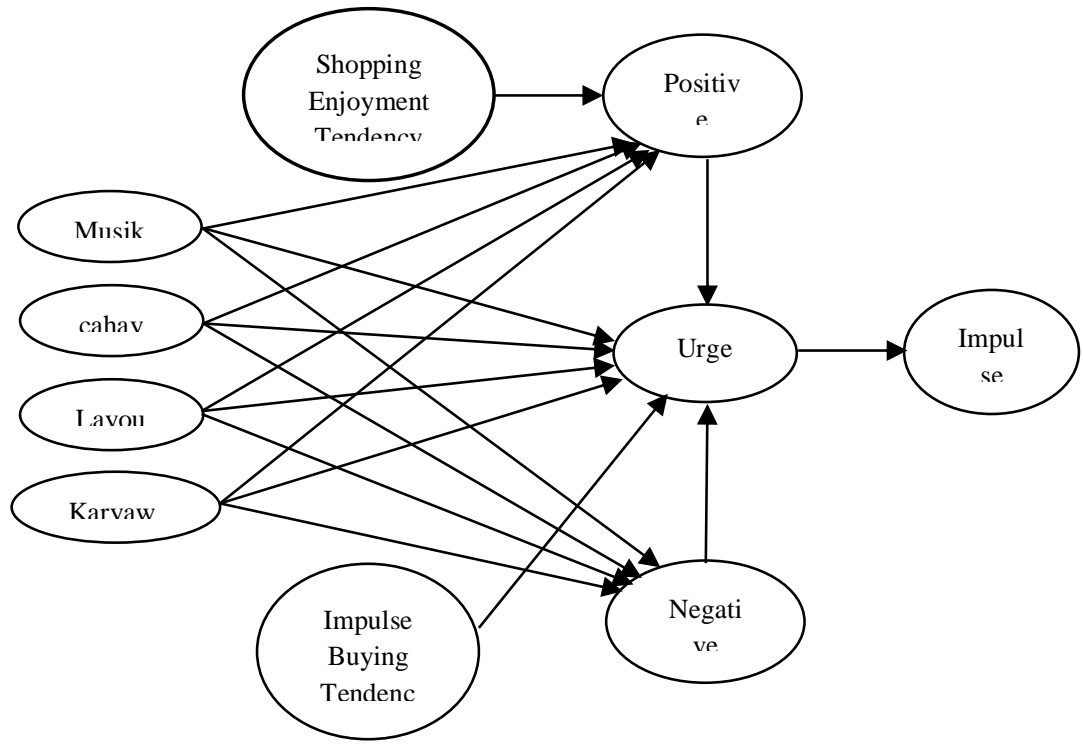

Sumber : Mohan, Sivakuraman \& Sharma (2013)

\section{MUSIK DAN POSITIVE AFFECT}

Menurut Jain \& Rajnish (2011), Musik telah diamati sebagai rangsangan yang kuat dalam membentuk ritel experience. Musik juga digunakan untuk membentuk perhatian, identifikasi, asosiasi dan pengingat di ritel. Sebagai kunci dari ambient factors di dalam lingkungan toko ritel, musik terlibat dalam menghibur, memberikan energi, menyegarkan, serta menciptakan pengalaman yang tak terlupakan bagi konsumen. Berdasarkan penjelasan diatas maka peneliti menghipotesiskan:

$\mathrm{Hl}$ : Terdapat pengaruh signifikan variabel musik terhadap variabel Positive Affect

\section{PENCAHAYAAN DAN POSITIVE AFFECT}

Summers \& Hebbert (2001 dalam Hulten 2012) menunjukkan bahwa pencahayaan terhadap displays memiliki efek positif dalam perilaku konsumen. Yang mana para pelaku bisnis ritel dapat mengembangkan pencahayaan di dalam toko sehingga dapat menarik konsumen dan mempertahankan konsumen. Kemudian ditambahkan oleh Utami (2010) yang menyatakan bahwa selain dapat membantu dalam menarik konsumen dan mempertahankan konsumen, pencahayaan yang baik juga dapat memberikan suasana tenang dan dapat menyembunyikan kesalahan dan Layout yang kurang bagus. Berdasarkan penjelasan diatas maka peneliti menghipotesiskan:

$\mathrm{H} 2$ : Terdapat pengaruh signifikan variabel pencahayaan terhadap variabel Positive Affect

\section{LAYOUT DAN POSITIVE AFFECT}

Menurut Titus \& Everett (1995 dalam Baker et al. 2002) Layout merupakan contoh dari aspek design yang mempengaruhi ekspetasi Layout konsumen dalam pergerakan yang efisien di dalam toko. Ditambahkan oleh Spies et al. (1998 dalam Mohan et al. 2013) yang menyatakan bahwa Layout yang baik akan membuat konsumen mudah menemukan barang yang dicari didalam, dan hal tersebut akan menimbulkan pengaruh positif. Berdasarkan penjelasan diatas maka peneliti menghipotesiskan:

H3 : Terdapat pengaruh signifikan variabel Layout terhadap variabel Positive Affect 


\section{KARYAWAN DAN POSITIVE AFFECT}

Menurut Eroglu \& Machleit (1990 dalam Baker et al. 2002), karyawan merupakan salah satu dari unsur sosial. Karyawan dapat memainkan peranan yang penting dalam mempengaruhi mood dan kepuasan konsumen seperti selalu tersenyum dan selalu ada ketika konsumen membutuhkan (Grewal \& Sharma 1991 dalam Baker et al. 2002). Berdasarkan penjelasan diatas maka peneliti menghipotesiskan:

H4 : Terdapat pengaruh signifikan variabel karyawan terhadap variabel Positive Affect

\section{MUSIK DAN NEGATIVE AFFECT}

Menurut d'Astous (2000), Musik yang terlalu kencang atau musik yang tidak sesuai dengan tempatnya akan dapat menggangu konsumen pada saat berbelanja yang mana dapat menghasilkan pengaruh negative atau Negative Affect, Berdasarkan penjelasan diatas maka peneliti menghipotesiskan:

H5 : Terdapat pengaruh signifikan variabel musik terhadap variabel Negative Affect

\section{PENCAHAYAAN DAN NEGATIVE AFFECT}

Menurut Mohan et al. 2013 dalam menciptakan pencahayaan yang baik didalam toko, manajemen perusahaan dapat mengadopsi pencahayaan yang cocok dengan barangbarang yang dijual agar konsumen dapat melihat atau memeriksa barang dengan baik. Pencahayaan yang tidak baik akan menyusahkan konsumen dalam mengidentifikasi barang dan akan menimbulkan pengaruh negative, Berdasarkan penjelasan diatas maka peneliti menghipotesiskan:

H6 : Terdapat pengaruh signifikan variabel pencahayaan terhadap variabel Negative Affect

\section{LAYOUT DAN NEGATIVE AFFECT}

Menurut Jones (1999 dalam Mohan et al. 2013), Layout yang buruk akan dapat menimbulkan pengaruh negatif karena konsumen kebingungan dalam mencari barang yang dicari atau konsumen merasa ruang geraknya didalam toko sangat terbatas.

Berdasarkan penjelasan diatas maka peneliti menghipotesiskan:

H7 : Terdapat pengaruh signifikan variabel Layout terhadap variabel Negative Affect

\section{KARYAWAN DAN NEGATIVE AFFECT}

Menurut Oliver dan Swan (1989), Kebiasaan dan perilaku seorang tenaga penjual di dalam sebuah toko dapat mempengaruhi tingkat kepuasan dari konsumen terhadap tenaga penjual itu sendiri serta ritelnya dan kepuasan konsumen tentunya berdasarkan pengaruh negatif maupun positif yang didapat didalam toko. Apabila tenaga penjual tersebut buruk maka tentunya akan menghasilkan pengaruh yang negative, berdasarkan penjelasan diatas maka peneliti menghipotesiskan:

H8 : Terdapat pengaruh signifikan variabel karyawan terhadap variabel Negative Affect

\section{MUSIK DAN URGE TO BUY IMPULSIVELY}

Musik merupakan salah satu unsur dari lingkungan toko yang sangat penting dalam komunikasi secara non-verbal, biasanya digunakan untuk menghasilkan atmosfer toko yang nyaman dan terkadang juga dapat membuat pembelian tak terencana (Turley dan Milliman 2000 dalam Mohan et al. 2013). Berdasarkan penjelasan diatas maka peneliti menghipotesiskan: 
Teofilus

Steven $\mathrm{Ng}$

H9 : Terdapat pengaruh signifikan variabel musik terhadap variabel Urge to buy impulsively

\section{PENCAHAYAAN DAN URGE TO BUY IMPULSIVELY}

Teknik pencahayaan yang baik dapat membantu menciptakan ambience yang baik seperti yang terjadi di restoran dan toko yang memiliki pencahayaan yang baik dapat menciptakan minat agar konsumen berkunjung dan terjadinya keinginan untuk melakukan pembelian yang tak terencana (Mohan et al. 2013). Berdasarkan penjelasan diatas maka peneliti menghipotesiskan:

H10 : Terdapat pengaruh signifikan variabel pencahayaan terhadap variabel Urge to buy impulsively

\section{LAYOUT DAN URGE TO BUY IMPULSIVELY}

Menurut Aghazadeh (2005 dalam Mohan et al. 2013) Layout yang optimal dapat membuat konsumen melakukan keinginan untuk melakukan pembelian tak terencana karena konsumen dapat dengan mudah melihat barang-barang yang ada ditoko ditata dengan baik dan memiliki hubungan dengan barang-barang yang berada didekatnya. Berdasarkan penjelasan diatas maka peneliti menghipotesiskan:

H11: Terdapat pengaruh signifikan variabel Layout terhadap variabel Urge to buy impulsively

\section{KARYAWAN DENGAN URGE TO BUY IMPULSIVELY}

Menurut Mohan et al. (2013), tenaga penjual dapat membawa konsumen untuk berkeliling toko dan melihat barang-barang yang dijual didalam toko yang mana akan dapat menimbulkan keinginan untuk melakukan pembelian barang yang tidak direncanakan.

Berdasarkan penjelasan diatas peneliti menghipotesiskan:

H12 : Terdapat pengaruh signifikan variabel karyawan terhadap variabel Urge to buy impulsively

\section{SHOPPING ENJOYMENT TENDENCY DAN POSITIVE AFFECT}

Shopping Enjoyment Tendency menurut Beatty \& Ferrell (1998) adalah sebagai perasaan senang seseorang yang di dapatkan dalam proses berbelanja. Konsumen juga mendapatkan kegembiraan dan kesenangan dari kegiatan berbelanja (Babin, Darden \& Griffin 1994 dalam Mohan et al. 2013). Berdasarkan penjelasan diatas maka peneliti menghipotesiskan:

H13: Terdapat pengaruh signifikan variabel Shopping Enjoyment Tendency terhadap variabel Positive Affect.

\section{IMPULSE BUYING TENDENCY DAN URGE TO BUY IMPULSIVELY}

Menurut Weun, Jones \& Beatty (1998 dalam Park \& Lennon 2006) Impulse Buying tendency adalah tingkat dimana individu melakukan pembelian yang tidak diinginkan, segera, dan unreflective. Impulse Buying tendency sebagai bagian dari sifat pribadi dapat lebih intensif dalam konteks televison shopping programme. Television shopping programme dapat membuat situasi pembelian tak terduga karena konsumen tidak berencana untuk membeli sebelumnya dan konsumen kecenderungan akan memutuskan saat pemaparan berbagai macam produk (Stephens et al. 1996 dalam Park \& Lennon 2006). Berdasarkan penjelasan diatas maka peneliti menghipotesiskan:

H14: Terdapat pengaruh signifikan variabel Impulse Buying tendency terhadap variabel Urge to buy impulsively 


\section{POSITIVE AFFECT DAN URGE TO BUY IMPULSIVELY}

Berdasarkan hasil penelitian Mohan et al. 2013 yang menemukan bahwa Positive Affect memiliki pengaruh terhadap keinginan untuk melakukan pembelian yang tidak direncanakan maka peneliti menghipotesiskan:

H15: Terdapat pengaruh signifikan variabel Positive Affect terhadap variabel Urge to buy impulsively

\section{NEGATIVE AFFECT DAN URGE TO BUY IMPULSIVELY}

Menurut Yoan dan Faber (2000 dalam Mohan et al. 2013), Pengaruh negatif dapat menimbulkan keinginan untuk melakukan pembelian yang tidak direncanakan karena seseorang yang sedang mengalami mengalami perasaan yang negatif dapat membeli barang yang dirasa dapat mengurangi perasaan negatif atau membangun perasaan yang positif.

Berdasarkan penjelasan diatas maka peneliti menghipotesiskan.

H16: Terdapat pengaruh signifikan variabel Negative Affect terhadap variabel Urge to buy impulsively

\section{URGE TO BUY IMPULSIVELY DAN IMPULSE BUYING}

Berdasarkan penelitian sebelumnya (Beauty dan Ferrel 1998) diketahui bahwa konsumen yang merasakan keinginan untuk melakukan pembelian yang tidak direncanakan selama mengelilingi toko kebanyakan tidak dapat menahan diri sendiri yang akhirnya melakukan pembelian yang tidak direncanakan walaupun mereka sudah mencoba untuk mengkontrol diri mereka sendiri. Berdasarkan penjelasan di atas maka peneliti menghipotesiskan:

H17: Terdapat pengaruh signifikan variabel Urge to buy impulsively terhadap variabel Impulse Buying

\section{METODE PENELITIAN}

\section{SUBJEK PENELITIAN}

Subjek penelitian adalah data survei yang sifatnya mendetil, karena survei menyediakan apa yang kita perlukan. Survei adalah cara utama untuk mendapatkan informasi tentang motivasi, sikap dan preferensi konsumen (Malhotra 2012: 160). Dalam penelitian ini subjek yang diambil adalah konsumen Giant Ekstra Jatiasih.

\section{OBJEK PENELITIAN}

Objek yang akan digunakan dalam penelitian ini adalah gerai ritel Giant Ekstra Jatiasih. Pemilihan gerai Giant sebagai objek penelitian karena Giant cukup dikenal luas sehingga diharapkan dapat mempermudah dalam mendapatkan responden. Selain itu menurut hasil observasi dan wawancara peneliti, Terdapat beberapa masalah yang berkatian dengan faktor-faktor tersebut seperti jumlah karyawan di Giant Ekstra Jatiasih di bawah jumlah standar yang ditetapkan oleh kantor pusat dan bagian yang kosong adalah kasirseringkali terdapat bagian yang kosong dan tidak didisplay dengan baik.

\section{SAMPEL}

Dari beberapa metode pengambilan sampel yang ada, Metode pengambilan sampel yang dilakukan dalam penelitian ini adalah metode non-probabilitas dan dengan menggunakan pengambilan sampel keputusan (judgment sampling) karena merupakan tekhnik pengambilan sampel yang memiliki daya tarik dan kelebihan dimana peneliti dapat 


\section{Teofilus}

\section{Steven $\mathrm{Ng}$}

mendapatkan informasi yang memang diperlukan untuk penelitian karena sampling yang diambil memiliki kapasitas untuk menyediakan infomasi yang dibutuhkan. Oleh karena itu peneliti memilih sampel dengan kriteria konsumen Giant Ekstra Jatiasih, Bekasi, dengan jumlah sampel sebanyak 671 responden.

\section{HASIL DAN PEMBAHASAN UJI KOEFISIEN DETERMINASI}

Tabel 4.1

\begin{tabular}{|c|c|}
\hline & R Square \\
\hline Employee & \\
\hline IB & 0,763194 \\
\hline IBT & \\
\hline Layout & \\
\hline Light & \\
\hline Musik & \\
\hline Negative A & 0,072545 \\
\hline Positive Affect & 0,407541 \\
\hline SET & \\
\hline Urge & 0,283643 \\
\hline
\end{tabular}

Sumber : Hasil Pengolahan Data 671 Responden dengan SMART-PLS (2015)

Berdasarkan tabel diatas, hasil ini menunjukkan bahwa Impulse Buying dipengaruhi oleh variabel Urge to buy impulsively sebesar 0,7631 atau $76,31 \%$ dan dipengaruhi faktor lain yang tidak diteliti dalam penelitian ini sebesar $33,69 \%$. Hasil lain yang didapat adalah variabel Negative Affect yang dipengaruhi oleh variabel musik, pencahayaan, Layout, dan karyawan memiliki nilai sebesar 0,0725 atau sebesar $7,25 \%$ dan $92,75 \%$ nya dipengaruhi oleh faktor lain yang tidak ada didalam penelitian ini.

Variabel Positive Affect dipengaruhi oleh musik, pencahayaan, Layout, karyawan dan Shopping Enjoyment Tendency memiliki nilai sebesar 0,4075 atau sebesar $40,75 \%$ dan sisanya $49,25 \%$ dipengaruhi faktor lain yang tidak ada didalam penelitian ini. Dan untuk variabel Urge to buy impulsively yang dipengaruhi oleh Positive Affect, Negative Affect, Impulse Buying tendency, musik, pencahayaan, Layout, dan karyawan adalah sebesar 0,2836 atau sebesar $28,36 \%$ dan sisanya $71,64 \%$ dipengaruhi faktor lain yang tidak ada didalam model penelitian ini. 


\section{UJI † STATISTIK}

Tabel 4.2

Uji t-statistik

\begin{tabular}{|l|c|l|l|}
\hline Pengaruh & Hipotesis & Hasil Uji & Status \\
\hline \multicolumn{4}{|l|}{} \\
\hline Musik terhadap Positive Affect & $\mathrm{H} 1$ & 5,360124 & Diterima \\
\hline Pencahayaan terhadap Positive Affect & $\mathrm{H} 2$ & 0,467147 & Ditolak \\
\hline Layout terhadap Positive Affect & $\mathrm{H} 3$ & 6,073839 & Diterima \\
\hline Karyawan terhadap Positive Affect & $\mathrm{H} 4$ & 2,491362 & Diterima \\
\hline Musik terhadap Negative Affect & $\mathrm{H} 5$ & 0,177421 & Ditolak \\
\hline Pencahayaan terhadap Negative Affect & $\mathrm{H} 6$ & 0,022229 & Ditolak \\
\hline Layout terhadap Negative Affect & $\mathrm{H} 7$ & 2,983332 & Diterima \\
\hline Karyawan terhadap Negative Affect & $\mathrm{H} 8$ & 3,731985 & Diterima \\
\hline Musik terhadap Urge to buy impulsively & $\mathrm{H} 9$ & 1,429863 & Ditolak \\
\hline Pencahayaan terhadap Urge to buy impulsively & $\mathrm{H} 10$ & 0,440083 & Ditolak \\
\hline Layout terhadap Urge to buy impulsively & $\mathrm{H} 11$ & 2,163146 & Diterima \\
\hline Karyawan terhadap Urge to buy impulsively & $\mathrm{H} 12$ & 0,217973 & Ditolak \\
\hline Shopping Enjoyment Tendency terhadap Positive Affect & $\mathrm{H} 13$ & 4,977778 & Diterima \\
\hline Impulse Buying Tendency terhadap Urge to buy impulsively & $\mathrm{H} 14$ & 10,33981 & Diterima \\
\hline Positive Affect terhadap Urge to buy impulsively & $\mathrm{H} 15$ & 0,832075 & Ditolak \\
\hline Negative Affect terhadap Urge to buy impulsively & $\mathrm{H} 16$ & 1,392255 & Ditolak \\
\hline Urge to buy impulsively terhadap Impulse Buying & $\mathrm{H} 17$ & 65,24367 & Diterima \\
\hline
\end{tabular}

Sumber : Hasil Pengolahan Data 671 Responden dengan SMART-PLS (2015)

Berdasarkan hasil uji t-statistik yang telah diringkas dan dengan nilai tingkat kepercayaan yang telah ditetapkan yaitu $95 \%$ atau t-tabel sebesar 1,96. Maka dapat disimpulkan sebagai berikut:

\section{UJI HIPOTESIS 1.}

Berdasarkan hasil uji t-statistik yang telah dilakukan maka didapatkan hasil bahwa $\mathrm{Hl}$ diterima karena nilai nya lebih besar dari t tabel yaitu 5,360124 > 1,96. Hal tersebut sesuai teori yang ada dimana menurut Garlin dan Owen (2006 dalam Mohan et al. 2013) bahwa dengan adanya kehadiran dari musik yang menyenangkan maka juga akan timbul pengararuh positif atau positive afffect. Dengan demikian bahwa dapat dikatakan Validitas nomological terpenuhi pada uji hipotesis pertama.

\section{UJI HIPOTESIS 2.}

Berdasarkan hasil uji t-statistik yang telah dilakukan maka didapatkan hasil bahwa H2 ditolak karena nilai nya lebih kecil dari t tabel yaitu 0,467147<1,96. Hal ini berarti bahwa pencahayaan di Giant Ekstra Jatiasih tidak memiliki pengaruh yang signifikan terhadap Positive Affect, Pencahayaan di Giant Ekstra Jatiasih dapat dibilang standar dimana lampu yang digunakan memang hanya dimaksudkan sebagai penerangan ruangan secara keseluruhan karena memang barang-barang yang dijual adalah barang consumer goods atau kebutuhan sehari-hari sehingga tidak memberikan efek yang signifikan terhadap 
Teofilus

Steven $\mathrm{Ng}$

Positive Affect. Dengan demikian dapat dikatakan bahwa Validitas nomological untuk uji hipotesis kedua tidak terpenuhi.

\section{UJI HIPOTESIS 3.}

Berdasarkan hasil uji t-statistik yang telah dilakukan maka didapatkan hasil bahwa $\mathrm{H} 3$ diterima karena nilai nya lebih besar dari t tabel yaitu 6,073839>1,96. Hal tersebut berarti bahwa Layout dari Giant Ekstra Jatiasih memberikan pengaruh yang signifikan terhadap Positive Affect. Hal tersebut sesuai dengan teori yang dikemukakan oleh Spies et al. (1998 dalam Mohan et al. 2013) yang menyatakan bahwa Layout yang baik akan membuat konsumen mudah menemukan barang yang dicari didalam, dan hal tersebut akan menimbulkan pengaruh positif. Dengan demikian dapat dikatakan pada uji hipotesis ketiga, Validitas nomological terpenuhi.

\section{UJI HIPOTESIS 4.}

Berdasarkan hasil uji t-statistik yang telah dilakukan maka didapatkan hasil bahwa $\mathrm{H} 4$ diterima karena nilai nya lebih besar dari t tabel yaitu 2,491362 > 1,96. Hal tersebut berarti bahwa Karyawan dari Giant Ekstra Jatiasih memberikan pengaruh yang signifikan terhadap Positive Affect. Hal tersebut sesuai dengan teori yang dikemukakan oleh Eroglu \& Machleit (1990 dalam Baker et al. 2002) yang menyatakan bahwa karyawan memainkan peranan yang penting dalam mempengaruhi mood dan kepuasan konsumen (Grewal \& Sharma 1991 dalam Baker et al. 2002). Dengan demikian dapat dikatakan pada uji hipotesis keempat, Validitas nomological terpenuhi.

\section{UJI HIPOTESIS 5.}

Berdasarkan hasil uji t-statistik yang telah dilakukan maka didapatkan hasil bahwa H5 ditolak karena nilai nya lebih kecil dari t tabel yaitu $0,177421<1,96$. Hal tersebut berarti bahwa Musik dari Giant Ekstra Jatiasih tidak memberikan pengaruh yang signifikan terhadap Negative Affect. Hal tersebut dapat saja terjadi karena memang musik yang diputar di Giant Ekstra Jatiasih merupakan musik dengan standar nasional Indonesia dan diperdengarkan secara terus menerus dari buka sampai tutup toko agar suasana toko menjadi tidak hening atau sepi. Dengan demikian dapat dikatakan pada uji hipotesis kelima, Validitas nomological terpenuhi.

\section{UJI HIPOTESIS 6.}

Berdasarkan hasil uji t-statistik yang telah dilakukan maka didapatkan hasil bahwa H6 ditolak karena nilai nya lebih kecil dari $\dagger$ tabel yaitu 0,02229 < 1,96. Hal tersebut berarti bahwa Pencahayaan dari Giant Ekstra Jatiasih tidak memberikan pengaruh yang signifikan terhadap Negative Affect. Dengan demikian dapat dikatakan pada uji hipotesis keenam, Validitas nomological terpenuhi.

\section{UJI HIPOTESIS 7.}

Berdasarkan hasil uji t-statistik yang telah dilakukan maka didapatkan hasil bahwa H7 diterima karena nilai nya lebih besar dari t tabel yaitu 2,983332 $>1,96$. Hal tersebut berarti bahwa Layout dari Giant Ekstra Jatiasih memberikan pengaruh yang signifikan terhadap Negative Affect.

Hal tersebut dapat terjadi karena jika waktu akhir minggu atau awal bulan, Giant Ekstra Jatiasih sangat ramai dikunjungi konsumen dan menyebabkan kondisi di dalam toko menjadi sangat ramai dan Layout dari penempatan kasir dengan rak reguler tidak memiliki jarak yang cukup sehingga antrian sangat panjang dan menutupi jalan sehingga konsumen 
lain kesulitan untuk berjalan dan hal tersebut memberikan pengaruh yang negatif. Dengan demikian dapat dikatakan pada uji hipotesis ketujuh, Validitas nomological terpenuhi.

\section{UJI HIPOTESIS 8.}

Berdasarkan hasil uji t-statistik yang telah dilakukan maka didapatkan hasil bahwa $\mathrm{H} 8$ diterima karena nilai nya lebih besar dari † tabel yaitu 3,731985 > 1,96. Hal tersebut berarti bahwa Karyawan dari Giant Ekstra Jatiasih memberikan pengaruh yang signifikan terhadap Negative Affect. Dengan demikian dapat dikatakan pada uji hipotesis kedelapan, Validitas nomological terpenuhi.

\section{UJI HIPOTESIS 9.}

Berdasarkan hasil uji t-statistik yang telah dilakukan maka didapatkan hasil bahwa H9 ditolak karena nilai nya lebih kecil dari t tabel yaitu 1,429863 < 1,96. Hal tersebut berarti bahwa Musik dari Giant Ekstra Jatiasih tidak memberikan pengaruh yang signifikan terhadap Urge to buy impulsively. Dengan demikian dapat dikatakan pada uji hipotesis kesembilan, Validitas nomological tidak terpenuhi.

\section{UJI HIPOTESIS 10.}

Berdasarkan hasil uji t-statistik yang telah dilakukan maka didapatkan hasil bahwa $\mathrm{H} 10$ ditolak karena nilai nya lebih kecil dari t tabel yaitu 0,440083 < 1,96. Hal tersebut berarti bahwa Pencahayaan dari Giant Ekstra Jatiasih tidak memberikan pengaruh yang signifikan terhadap Urge to buy impulsively. Hal tersebut dapat terjadi karena memang tipe Pencahayaan di Giant Ekstra Jatiasih yang menyeluruh artinya semua barang-barang yang dijual tidak diberikan pencahayaan yang khusus berbeda dengan bisnis ritel lain seperti furniture atau perhiasan yang memang menggunakan pencahayaan sebagai daya tarik agar konsumen membeli barang-barang yang dijual, Dengan demikian untuk uji hipotesis kesepuluh, Validitas nomological tidak terpenuhi.

\section{UJI HIPOTESIS 11.}

Berdasarkan hasil uji t-statistik yang telah dilakukan maka didapatkan hasil bahwa $\mathrm{H} 11$ diterima karena nilai nya lebih besar dari t tabel yaitu 2,163146>1,96. Hal tersebut berarti bahwa Layout dari Giant Ekstra Jatiasih memberikan pengaruh yang signifikan terhadap Urge to buy impulsively. Hal tersebut dapat terjadi karena memang Layout di Giant Ekstra Jatiasih sudah memiliki standar yang telah ditetapkan Kantor pusatsehingga setiap gondola atau rak memiliki keterkaitan yang mengakibatkan konsumen dapat dengan mudah mencari barang yang dibutuhkan serta Manajemen juga menempatkan floor merchandise disepanjang rak yang dapat membuat konsumen merasakan dorongan untuk membeli, Dengan demikian untuk uji hipotesis kesebelas, Validitas nomological terpenuhi.

\section{UJI HIPOTESIS 12.}

Berdasarkan hasil uji t-statistik yang telah dilakukan maka didapatkan hasil bahwa $\mathrm{H} 12$ diterima karena nilai nya lebih besar dari t tabel yaitu 0,217973<1,96. Hal tersebut berarti bahwa Karyawan dari Giant Ekstra Jatiasih tidak memberikan pengaruh yang signifikan terhadap Urge to buy impulsively. Dengan demikian untuk uji hipotesis kedua belas, Validitas nomological tidak terpenuhi.

\section{UJI HIPOTESIS 13.}

Berdasarkan hasil uji t-statistik yang telah dilakukan maka didapatkan hasil bahwa $\mathrm{H} 13$ diterima karena nilai nya lebih besar dari † tabel yaitu 4,977778 >1,96. Hal tersebut berarti 


\section{Teofilus}

\section{Steven $\mathrm{Ng}$}

bahwa Shopping Enjoyment Tendency memberikan pengaruh yang signifikan terhadap Urge to buy impulsively. Hal tersebut dapat terjadi karena sesuai teori yang dikemukakan oleh Beatty \& Ferrell (1998) dimana Shopping Enjoyment Tendency adalah perasaan senang seseorang yang di dapatkan dalam proses berbelanja. Konsumen juga mendapatkan kegembiraan dan kesenangan dari kegiatan berbelanja (Babin, Darden \& Griffin 1994 dalam Mohan et al. 2013). Dengan demikian untuk uji hipotesis ketiga belas, Validitas nomological terpenuhi.

\section{UJI HIPOTESIS 14.}

Berdasarkan hasil uji t-statistik yang telah dilakukan maka didapatkan hasil bahwa $\mathrm{H} 14$ diterima karena nilai nya lebih besar dari t tabel yaitu 10,33981 > 1,96. Hal tersebut berarti bahwa Impulse Buying Tendency memberikan pengaruh yang signifikan terhadap Urge to buy impulsively. Hal tersebut dapat terjadi karena sesuai teori yang dikemukakan oleh Weun, Jones \& Beatty. (1998 dalam Park \& Lennon, 2006) Impulse Buying Tendency adalah tingkat dimana individu melakukan pembelian yang tidak diinginkan, segera, dan unreflective. Sehingga apabila seseorang yang memiliki tingkat Impulse Buying Tendency yang tinggi maka akan lebih besar kemungkinan untuk melakukan pembelian yang tidak direncanakan. Dengan demikian untuk uji hipotesis keempat belas, Validitas nomological terpenuhi.

\section{UJI HIPOTESIS 15.}

Berdasarkan hasil uji t-statistik yang telah dilakukan maka didapatkan hasil bahwa H15 ditolak karena nilai nya lebih kecil dari t tabel yaitu 0,832075 $<1,96$. Hal tersebut berarti bahwa Positive Affect tidak memberikan pengaruh yang signifikan terhadap Urge to buy impulsively. Dengan demikian untuk uji hipotesis kelima belas, Validitas nomological tidak terpenuhi.

\section{UJI HIPOTESIS 16.}

Berdasarkan hasil uji t-statistik yang telah dilakukan maka didapatkan hasil bahwa H16 ditolak karena nilai nya lebih kecil dari t tabel yaitu 1,392255 < 1,96. Hal tersebut berarti bahwa Negative Affect tidak memberikan pengaruh yang signifikan terhadap Urge to buy impulsively. Dengan demikian untuk uji hipotesis keenam belas, Validitas nomological terpenuhi.

\section{UJI HIPOTESIS 17.}

Berdasarkan hasil uji t-statistik yang telah dilakukan maka didapatkan hasil bahwa H17 diterima karena nilai nya lebih besar dari t tabel yaitu 65,24367 >1,96. Hal tersebut berarti bahwa Urge to buy impulsively memberikan pengaruh yang signifikan terhadap Impulse Buying. Dengan demikian untuk uji hipotesis ketujuh belas, Validitas nomological terpenuhi.

\section{SIMPULAN}

Dari penelitian ini dapat disimpulkan bahwa terdapat beberapa variabel yang memberikan pengaruh signifikan seperti, Musik terhadap Positive Affect, Layout terhadap Positive Affect, Karyawan terhadap Positive Affect, Layout terhadap Negative Affect, Karyawan terhadap Negative Affect, Layout terhadap Urge to buy impulsively, Shopping Enjoyment Tendency terhadap Positive Affect, Impulse Buying Tendency terhadap Urge to buy impulsively, Urge to buy impulsively terhadap Impulse Buying. 


\section{SARAN}

Saran yang diberikan peneliti, Terkait penelitian yang telah dilakukan adalah:

1. Bagi dunia akademis sebaiknya dapat lebih mengembangkan pengetahuan dan wawasan tentang bagaimana cara membuat lingkungan toko (musik, pencahayaan, Layout dan karyawan) yang menarik sehingga dapat memberikan pengaruh positif untuk konsumen dan diharapkan dapat menciptakan pembelian yang tidak direncanakan.

2. Untuk penelitian selanjutnya mengenai lingkungan toko (musik, pencahayaan, Layout dan karyawan), Positive Affect, Negative Affect, Shopping Enjoyment Tendency, Impulse Buying tendency, Impulse Buying, diharapkan lebih memiliki pengembangan model seperti aspek ketersediaan nya vang, ketersediaan nya waktu, suhu ruangan, keramaian di dalam toko, visual merchandising, sales promotion dan pengembangan model lain nya. Diharapkan juga penelitian selanjutnya dapat memneliti objek penelitian yang lebih besar seperti sebuah pusat perbelanjaan atau mal.

3. Untuk penelitian selanjutnya diharapkan dapat lebih detail dan rinci dalam mendapatkan informasi responden seperti seberapa banyak dari barang yang dibeli oleh konsumen yang merupakan Impulse Buying sehingga dapat diketahui berapa ratarata persentase barang Impulse Buying di setiap konsumen melakukan kegiatan belanja di toko tersebut. 


\section{DAFTAR PUSTAKA}

Beatty, S. E., \& Ferrel, M. E. (1998). "Impulse Buying: Modeling its Precursors". Journal of Riteling, 169.

Cox, R., \& Brittain, P. (2000). "Ritel Management". Edinburgh Gate, England: Pearson Education Limited.

d' Astous, A. (2000). "Irritating aspects of the shopping environment". Journal of Business Research.

Dholakia, U. M. (2000). "Temptation and Resistance: An Integrated Model of Consumption Impulse Formation and Enacment". Psychology \& Marketing, 955.

Duarte, P., Raposo, M., \& Ferraz, M. (2013). "Drivers of snack foods impluse buying behaviour among young consumers". British Food Journal, Vol. 115 No. 9, 1233-1254.

Dunne, P. M., \& Lusch, R. F. (2008). "Riteling". South-Western: Thomson.

Hsu, C. H. (2010). "Spectator Visual Perception Scale for Lighting at In-line Hockey Rinks". The Business Review, Vol. 14, 120-127.

Hu, H., \& Jasper, C. R. (2006). "Social cues in the Store Environment and their impact on Store image". International Journal of Riteling \& Distributin Management, Vol. 34 No. 1, 2548.

Jain, R., \& Badgare, S. (2011). Music and consumption experience: a review". International Journal of Ritel \& Distribution Management, Vol. 39 No. 4, 289-302.

Kotler, P., \& Keller, K. L. (2012). "Marketing Management". New Jersey: Pretince Hall.

Malhotra, N. K. (2012). "Basic Marketing Research" (4th ed.). United states of America: Pretince Hall.

Mohan, G., Sivakuraman, B., \& Sharma, P. (2013). "Impact of Store Environment on Impulse Buying behaviour". Europian Journal of Marketing, Vol. 47, 1711-1732.

Oliver, R., \& Swan, J. (1989). Consumer perceptions of interpersonal equity and satisfaction in transactions: a field survey approach. Journal of Marketing.

Park, J., \& Lennon, S. J. (2006). "Psychological and environmental antecedents of Impulse Buying tendency in the multichannel shopping context". Journal of Consumer Marketing, 58-68.

Podoshen, J. S., \& Andrzejewski, S. A. (2012). "An Examination of The Relationships Between Materialism, Conspicuous Consumption, Impulse Buying and Brand Loyalty". Journal of Marketing Theory and Practice, Vol. 20, No.3, 319-333.

Silvera, D. H., Lavack, A. M., \& Kropp, F. (2008). "Impulse Buying: the role of affect, social influence, and subjective wellbeing". Journal of Consumer Marketing, 23-33.

Sweeney, J. C., \& Wyber, F. (2002). "The role of cognitions and emotions in the musicapproach-avoidance behaviour relationship". The Journal of Service Marketing, 51.

Utami, C. W. (2010). Manajemen Ritel: Strategi dan Implementasi Operasional Bisnis Ritel Modern di Indonesia. Jakarta: Salemba Empat.

Vrechopoulos, A. P., Keefe, R. M., Doukidis, G. I., \& Siomkos, G. J. (2004). "Virtual Store Layout: an experimental comparison in the context of grocery ritel". Journal of Riteling, 13-22.

Wells, J. D., Parboleeah, V., \& Valacich, J. S. (2011, January). "Online Implulse Buying: Understanding the interplay between Consumer Impulsiveness and Website Quality". Journal of the Association for Information Systems, Vol. 12, 32-56.

Wijaya, T. (2009). "Analisis Structural Equation Model menggunakan AMOS". Yogyakarta: Universitas Atma Jaya Yogyakarta. 